\title{
Long-term stability of curve of Spee levelled with continuous archwires in subjects with different vertical patterns: a retrospective study
}

\author{
Matteo Rozzi, Manuela Mucedero, Chiara Pezzuto, \\ Roberta Lione and Paola Cozza
}

Department of Clinical Sciences and Translation Medicine, University of Rome "Tor Vergata", Italy

Correspondence to: Manuela Mucedero, Department of Orthodontics, Fondazione Policlinico Tor Vergata (PTV), Viale Oxford 81, Rome 00133, Italy. E-mail: mmucede@tin.it

\section{Summary}

Objectives: The aim of the study was to evaluate the curve of Spee (COS) stability in patients treated with continuous archwires with different vertical patterns.

Methods: The study sample consisted of 60 patients $(28$ males, 32 females; mean age $19.8 \pm 1.4$ years) presenting with COS depth of at least $2 \mathrm{~mm}$ at baseline. For each subject, lateral cephalograms and dental casts were available before treatment (T1), at the end of orthodontic therapy (T2), and 2 years after the end of treatment (T3). All subjects were divided into three groups according to vertical facial patterns. Cephalometric parameters were used to evaluate the dental movements after treatment. COS depth was measured on digital casts. Mean differences between vertical facial subgroups were contrasted by means of analysis of variance test $(P<0.01)$. Results: In low-angle subjects, COS levelling occurred through advancement and intrusion of lower incisors, whereas in high-angle patients, the COS was flattened through extrusion and uprighting of lower posterior teeth. In the low-angle group, a significant relapse of lower incisors inclination was observed. Differently, the high-angle group exhibited a greater stability of COS obtained by stable extrusion of posterior teeth.

Conclusions: The long-term instability of flared incisors determined the relapse of overbite and cos depth in the low-angle group.

\section{Introduction}

Occlusal curvature in the sagittal plane, first described as curve of Spee (COS), has a biomechanical function during food processing by increasing the crush-to-shear ratio between the posterior teeth and the efficiency of occlusal forces during mastication (1).

However, Andrews (2) proposed the flattening of occlusal plane as a treatment goal in orthodontics to obtain a good and stable intercuspation. In the mandible, a deep COS can be levelled by extrusion of infraerupted premolars, intrusion of overerupted incisors, incisor advancement, or a combination of these movements. Rozzi et al. (3) showed that skeletal vertical pattern influences dental movements during COS levelling with continuous archwires. In particular, it was observed that in brachyfacial patients COS levelling occurred through buccal inclination and intrusion of mandibular incisors, whereas in dolichofacial subjects COS was flattened through extrusion and uprighting of mandibular posterior teeth.

Relatively little is known about the long-term stability of COS depth. Koyama (4) and Garcia (5) observed that after orthodontic treatment, the levelled curve tends to return towards its original position, often leading to undesirable relapse in overbite, mandibular incisor irregularity (4-6), and posterior occlusal interferences (7-9). Kuitert et al. (10) found that the original COS depth does not predict post-retention stability. After treatment, 50 per cent of the deepened curves improved, and 25 per cent of the flat curves deteriorated. Although attempts to correlate post-treatment changes with pre-treatment occlusal variables have been unsuccessful, there 
is still a need to correlate the COS post-retention changes with other craniofacial characteristics. Relapse may develop in some patients because the downward and forward mandibular growth continues longer than that of the upper jaw, forcing the lower anterior teeth back and up, or in other subjects because strong masticatory muscles tend to intrude posterior teeth.

Accordingly, if certain patients can be identified as high-risk candidates for overbite relapse, retention strategies might need to be altered for them to achieve the most stable outcomes (11). Therefore, the aim of this study was to analyse the long-term stability of COS depth in relation with different skeletal vertical patterns 2 years after the end of treatment with fixed appliances and continuous archwires. The hypothesis underlying this investigation is that the levelling of COS is obtained through different dental movements (i.e. molar extrusion, anterior teeth intrusion, proclination of lower incisors), and moreover, the stability of those movements depend on patient vertical dimension.

\section{Materials and methods}

The sample for this retrospective study consisted of 60 Caucasian patients ( 28 males; 32 females) with a mean age of $19.8 \pm 1.4$ years derived from the archives of the graduate orthodontic program at the University of Rome "Tor Vergata", Italy and treated between 2011 and 2014. This project was approved by the ethical committee at the University of Rome "Tor Vergata", Italy, (protocol number 58/16), and informed consent was obtained from parents. All subjects were selected according to the following inclusion criteria: full permanent dentition (excluded third molars), COS depth of at least $2 \mathrm{~mm}$ before treatment, Class I or Class II molar occlusion, moderate irregularity of anterior crowding according to the Little's Irregularity Index (12), and post-pubertal stage of skeletal maturity (CS6) (13). Exclusion criteria included subjects with skeletal Class III relationship, previous orthodontic treatment, periodontal disease or morphological tooth anomaly, dental restoration or crown, and mandibular asymmetry.

Each patient underwent a standardized non-extractive treatment protocol with full fixed conventional 0.022-in slot pre-adjusted edgewise brackets (McLaughlin-Bennett-Trevisi prescription $^{\mathrm{TM}}$ ) on all teeth including upper and lower second molars. Standard continuous archwire sequence with passive tiebacks during alignment and levelling phases [0.016-in round, $0.017 \times 0.025$-in rectangular, $0.019 \times 0.025$-in rectangular martensitic active nickel-titanium alloys (3M Unitek), and $0.019 \times 0.025$-in stainless steel] was used in all subjects. Alignment and levelling were considered finished when passive engagement of a $0.019 \times 0.025$-in stainless steel archwire was achieved. The subjects with Class II occlusion were treated with intermaxillary elastics. No auxiliary or reverse COS wires were applied during treatment. The patients received inter-proximal reduction of at least $1 \mathrm{~mm}$ performed on lower incisors. Treatment with fixed appliances was followed by 1 year retention (maxillary and mandibular Hawley retainers) in all subjects. The average active treatment time was $24 \pm 6$ months.

For all patients, dental casts and lateral cephalograms were available before treatment (T1), at the end of fixed therapy (T2), and at least 2 years after the end of treatment (T3).

The cephalometric radiographs were scanned into imaging software (version 11.0; Dolphin Imaging, Chatsworth, California, USA). Standard cephalometric landmarks and reference planes $(14,15)$ were then identified on each radiograph (Figure 1).

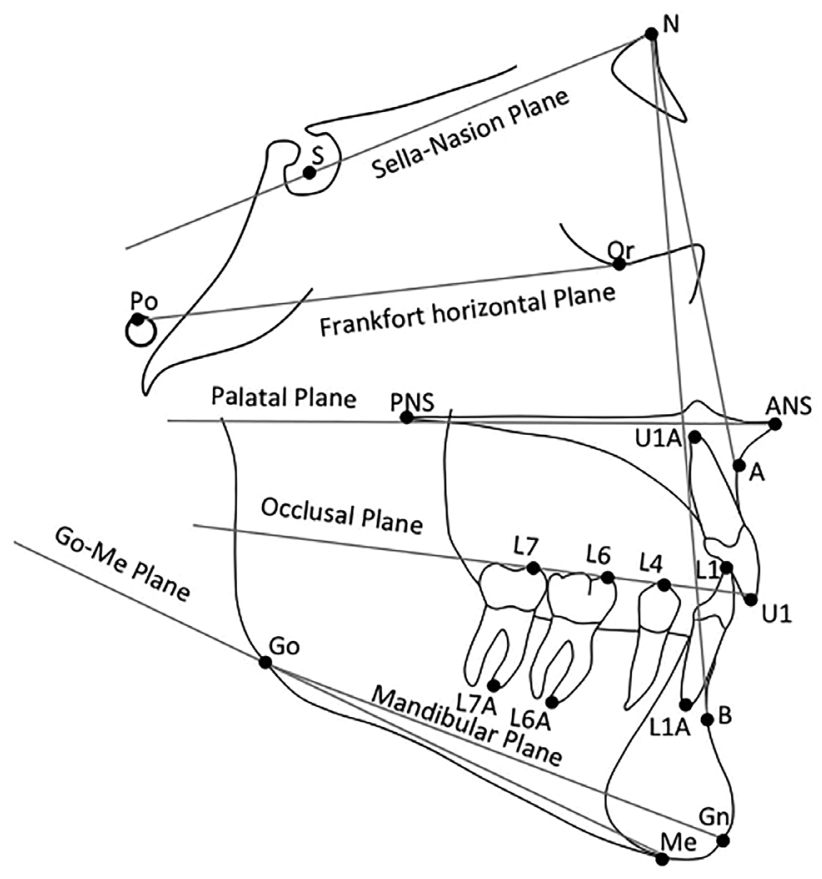

Figure 1. Landmarks and reference planes. $\mathrm{S}$, sella; $\mathrm{N}$, nasion; Po, porion; Or, orbitale; ANS, anterior nasal spine; PNS, posterior nasal spine; $A$, point $A ; B$, point $B ; \cup 1$, most proclined incisal edge of maxillary central incisor; $\mathrm{U} 1 \mathrm{~A}$, root apex of maxillary central incisor; L1, most proclined incisal edge of mandibular incisor; L1A, root apex of mandibular incisor; L4, most proclined cusp tip of the lower first premolar; L6, most proclined mesial cusp tip of the lower first permanent molar; L6A, mesial root apex of the lower first permanent molar; L7, most proclined mesial cusp tip of the lower second permanent molar; L7A, mesial root apex of the lower second permanent molar; Gn, gnathion; Me, menton; Go, gonion; sella-nasion plane (SN), line from $S$ to $N$; Frankfort horizontal plane (FP), line from Po to Or; palatal plane (PP), line from PNS to ANS; occlusal plane (OP), line drawn along the maximum intercuspation of the posterior teeth; mandibular plane (MP), line from Go to Gn; Go-Me plane, line from Go to Me.

The vertical position of the most proclined maxillary (U1) and mandibular central incisors (L1), mandibular first premolar (L4) and first (L6) and second (L7) molars was measured perpendicular to palatal and mandibular planes, respectively (11). The arch levelling was measured by the changes in the measurements of the distances of L1, L4, L6, and L7 to the mandibular plane. The cephalometric measurements used in this study are shown in Table 1 and Figure 2.

After data collection, patients were grouped according to their facial types (low-angle, normal-angle, and high-angle) based on pre-treatment values of y-axis, mandibular plane angle (FMA), and $\mathrm{SN}^{\wedge} \mathrm{GoGn}$ angle. Low-angle group consisted of 21 patients (10 males, 11 females; mean age of $19.9 \pm 1.4$ years) with a mandibular plane angle less than $23^{\circ}$, y-axis less than $63^{\circ}$, and $\mathrm{SN}^{\wedge} \mathrm{GoGn}$ angle less than $27^{\circ}$. Normal-angle group included 20 patients ( 9 males, 11 females; mean age of $20 \pm 1.3$ years) with a mandibular plane angle between $23^{\circ}$ and $28^{\circ}$, y-axis between $63^{\circ}$ and $69^{\circ}$, and $\mathrm{SN}^{\wedge} \mathrm{GoGn}$ angle between $27^{\circ}$ and $37^{\circ}$. High-angle group was composed of 19 patients ( 8 males, 11 females; mean age of $19.5 \pm 1.6$ years) with a mandibular plane angle greater than $28^{\circ}$, y-axis greater than $69^{\circ}$, and $\mathrm{SN}^{\wedge} \mathrm{GoGn}$ angle greater than $37^{\circ}$. It was decided arbitrarily that at least two of these three variables were required to determine facial type (Table 2) (3).

Dental casts were scanned with a three-dimensional scanner (D800, 3Shape A/S, Copenhagen K Denmark) with a scan time of 25 
Table 1. Definitions of cephalometric measurements

\begin{tabular}{|c|c|}
\hline Measurement & Definition \\
\hline \multicolumn{2}{|c|}{ Angular measurement } \\
\hline SNA $\left({ }^{\circ}\right)$ & Angle between SN plane and NA plane \\
\hline $\operatorname{SNB}\left({ }^{\circ}\right)$ & Angle between SN plane and NB plane \\
\hline $\operatorname{ANB}\left({ }^{\circ}\right)$ & Difference between SNA and SNB \\
\hline $\mathrm{SN}^{\wedge} \mathrm{GoGn}\left({ }^{\circ}\right)$ & Angle between SN plane and mandibular plane \\
\hline FMA $\left({ }^{\circ}\right)$ & Angle between FP plane and Go-Me plane \\
\hline $\mathrm{y}$-axis $\left({ }^{\circ}\right)$ & Angle between FP plane and line of S-Gn \\
\hline $\mathrm{SN}^{\wedge} \mathrm{OP}\left({ }^{\circ}\right)$ & Angle between SN plane and occlusal plane \\
\hline $\mathrm{OP}^{\wedge} \mathrm{MP}\left({ }^{\circ}\right)$ & Angle between occlusal plane and mandibular plane \\
\hline $\mathrm{SN}^{\wedge} \mathrm{PP}\left({ }^{\circ}\right)$ & Angle between SN plane and palatal plane \\
\hline $\operatorname{IMPA}\left({ }^{\circ}\right)$ & Angle between mandibular plane and line of L1-L1A \\
\hline Up.Inc. ${ }^{\wedge} \mathrm{FP}\left({ }^{\circ}\right)$ & Angle between FP plane and line of U1-U1A \\
\hline Int.Inc. $\left({ }^{\circ}\right)$ & Angle between line of U1-U1A and line of L1-L1A \\
\hline $\mathrm{L} 6^{\wedge} \mathrm{MP}\left({ }^{\circ}\right)$ & Angle between mandibular plane and line of L6-L6A \\
\hline $\mathrm{L} 7^{\wedge} \mathrm{MP}\left({ }^{\circ}\right)$ & Angle between mandibular plane and line of L7-L7A \\
\hline \multicolumn{2}{|c|}{ Linear measurement } \\
\hline $\mathrm{OVJ}(\mathrm{mm})$ & Sagittal linear distance from L1 to U1 \\
\hline OVB $(\mathrm{mm})$ & Vertical linear distance from L1 to U1 \\
\hline L1-MP (mm) & Linear distance from L1 to mandibular plane \\
\hline L4-MP (mm) & Linear distance from L4 to mandibular plane \\
\hline L6-MP (mm) & Linear distance from L6 to mandibular plane \\
\hline L7-MP (mm) & Linear distance from L7 to mandibular plane \\
\hline $\mathrm{U} 1-\mathrm{PP}(\mathrm{mm})$ & Linear distance from U1 to palatal plane \\
\hline
\end{tabular}

Refer to Figures 1 and 2 for the location of each landmarks.

seconds, resolution with two cameras at 5.0 megapixels, and ultrahighpoint accuracy less than $15 \mu \mathrm{m}$. Each cast was scanned from 10 or more views that were then combined and rendered into three dimensions with the software. The virtual three-dimensional models were measured with the software.

The COS depth was measured as follows: the distobuccal cusps of the left (DCL7) and right (DCR7) second molars and the midpoint between the central incisors (LII) served as the tripod landmarks; the occlusal plane, defined by the midpoint of the centre in the right and left incisor edges and the tips of the right and left second molar distobuccal cusps, was established in the mandibular dental arch. The perpendicular distances from the occlusal plane to the buccal cusp tip of each lateral tooth were measured. Measurements were obtained on the right (DPR) and left (DPL) sides in the deepest point of the curve. Landmarks, reference planes, and measurements used are shown in Figure 3. The premolar used to measure the deepest part of the COS had to be in occlusal contact with an opposing tooth in the maxillary dentition. The COS value was calculated as the sum of the COS on the right and left sides of the dental arch, and the deepest point was used as a representative value for the COS on each side.

\section{Statistical analysis}

The sample size for the treated groups was calculated considering a clinically significant difference of $1.0 \mathrm{~mm}$ in the COS value with a standard deviation of $0.6 \mathrm{~mm}$ and a power of 0.80 . The calculated sample size for the multicomparison analysis test was 19 subjects in each group. Data were analysed with conventional descriptive statistics. The normal distribution of the data was tested with the Kolmogorov-Smirnov test (Table 3). The hypothesis that the data were normally distributed could not be rejected for any variable.

To test the reliability of the measurements, 30 sets of threedimensional virtual models and lateral cephalograms were selected randomly, and the experimental procedure was repeated from the same operator (CP) 2 weeks later. The two sets of coordinates were compared using paired $t$-tests, evaluated with Bland-Altman plots (3) and were confirmed by Pearson and linear regression analyses. No significant systematic errors were found between the measurement sessions $(P>0.01)$. The method errors varied between $0.14^{\circ}$ and $0.59^{\circ}$ for the angular measurements, and between 0.17 and $0.63 \mathrm{~mm}$ for the linear measurements. A post hoc power test indicated an achieved power of 0.80 for the study. Multicomparison analysis of variance was used to determine whether there were differences between the changes in the groups with time. Variance analysis was then followed by pair-wise bivariate contrasts in the form of $t$-tests if a significant difference was found. The level of significance was set at $P$ value of greater than or equal to 0.01 for all statistical analyses.

\section{Results}

Analysis of the starting forms showed that the three groups had no statistically significant differences in craniofacial and dental characteristics at T1 (Table 4). The only exception was a significant difference between the groups for the vertical dimension $\left(\mathrm{SN}^{\wedge} \mathrm{GoGn}\right.$, FMA, y-axis).

No significant differences were found in the mean measurements for the pre-treatment COS depth for male and female patients, or between the right and left sides. No significant differences were detected for the pre-treatment COS depth between the three groups (Table 5).

\section{Comparison T2-T1}

No significant differences were found at $\mathrm{T} 2$ between the groups for any skeletal variables (Table 6).

When comparing the T2-T1 dental changes, there were no differences in the amount of COS and overbite correction between the different vertical facial patterns (OVB: $+3.37 \mathrm{~mm},+2.75 \mathrm{~mm}$, $+2.65 \mathrm{~mm}$ in low-, normal-, high-angle groups respectively). The average COS flattening ranged from $-2.87 \mathrm{~mm}$ in the low-angle group to $-2.08 \mathrm{~mm}$ in the high-angle group.

The low-angle group showed decreased clockwise rotation of the occlusal plane $\left(\mathrm{OP}^{\wedge} \mathrm{MP}:-1.23^{\circ}\right)$ with respect to the normal-angle $\left(\mathrm{OP}^{\wedge} \mathrm{MP}:-2.76^{\circ}\right)$ and the high-angle $\left(\mathrm{OP}^{\wedge} \mathrm{MP}:-3.40^{\circ}\right)$ groups.

A significantly increased proclination and intrusion movements of lower incisors were found in the low-angle group (L1-MP: $+2.03 \mathrm{~mm}$; IMPA: $+6.71^{\circ}$ ) when compared with the normal-angle (L1-MP: $+0.85 \mathrm{~mm}$; IMPA: $+1.72^{\circ}$ ) and the high-angle (L1-MP: $+0.26 \mathrm{~mm}$; IMPA: $\left.+0.54^{\circ}\right)$ groups.

The high-angle group presented smaller reduction of interincisal angle (Int.Inc.: $-2.75^{\circ}$ ) when compared to the normal-angle (Int. Inc.: $-6.27^{\circ}$ ) and the low-angle (Int.Inc.: $-5.83^{\circ}$ ) groups.

The high-angle group showed greater extrusion of posterior teeth (L4-MP: +3.62 mm; L6-MP: +2.24 mm) associated with uprighting of the first and second molars (L6^ $6^{\wedge}$ : $-4.00^{\circ}$; L $7^{\wedge} \mathrm{MP}:-3.38^{\circ}$ ) compared with the low-angle group (L4-MP: $+0.79 \mathrm{~mm}$; L6-MP: +0.45 mm; L6 $6^{\wedge} \mathrm{MP}:-1.82^{\circ}$; L7^ MP: $-1.78^{\circ}$ ).

\section{Comparison T3-T2}

No significant differences were found at T3 between the groups for any skeletal variables (Table 7).

When comparing the dental changes from T2 to T3, significant intergroup differences were also observed. 

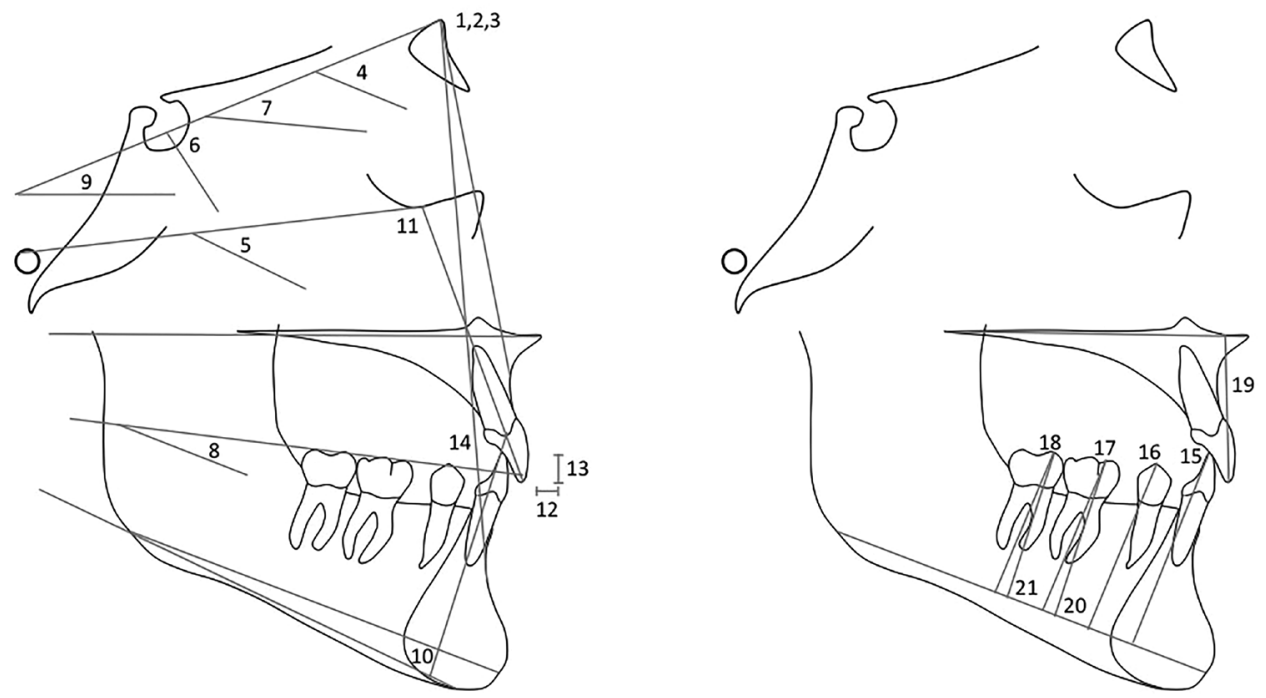

Figure 2. Cephalometric measurements. 1, SNA; 2, SNB; 3, ANB; 4, SN^GoGn; 5, FMA; 6, y-axis; 7, SN^OP; 8, OP^MP; 9, SN^PP; 10, IMPA; 11, Up.Inc.^FP; 12 , overjet (OVJ); 13, overbite (OVB); 14, interincisal angle (Int.Inc.); 15, L1-MP; 16, L4-MP; 17, L6-MP; 18, L7-MP; 19, U1-PP; 20, L6^MP; 21, L7^MP.

Table 2. Demographic and vertical skeletal characteristics of the three subgroups at $\mathrm{T} 1, \mathrm{~T} 2$, and $\mathrm{T} 3$

\begin{tabular}{|c|c|c|c|c|c|c|c|c|}
\hline \multirow[b]{2}{*}{ Groups } & \multicolumn{3}{|c|}{ Age (y) } & \multirow[b]{2}{*}{$\operatorname{FMA}\left({ }^{\circ}\right)$} & \multirow[b]{2}{*}{$\mathrm{SN}^{\wedge} \operatorname{GoGn}\left({ }^{\circ}\right)$} & \multirow[b]{2}{*}{$y$-axis $\left({ }^{\circ}\right)$} & \multirow{2}{*}{$\begin{array}{l}\text { Mean treatment } \\
\text { time (mo) }\end{array}$} & \multirow{2}{*}{$\begin{array}{l}\text { Mean post-retention } \\
\text { time }(\mathrm{y})\end{array}$} \\
\hline & T1 & $\mathrm{T} 2$ & T3 & & & & & \\
\hline Low-angle & 19.9 & 21.10 & 24.4 & 19.4 & 27.8 & 56.2 & 25 & 2.6 \\
\hline Normal-angle & 20.1 & 22.1 & 24.10 & 26.7 & 33.3 & 58.8 & 24 & 2.9 \\
\hline High-angle & 19.5 & 21.4 & 23.8 & 33.9 & 42.4 & 63.6 & 23 & 2.4 \\
\hline
\end{tabular}

Refer to Table 1 for the definition of cephalometric measurements.
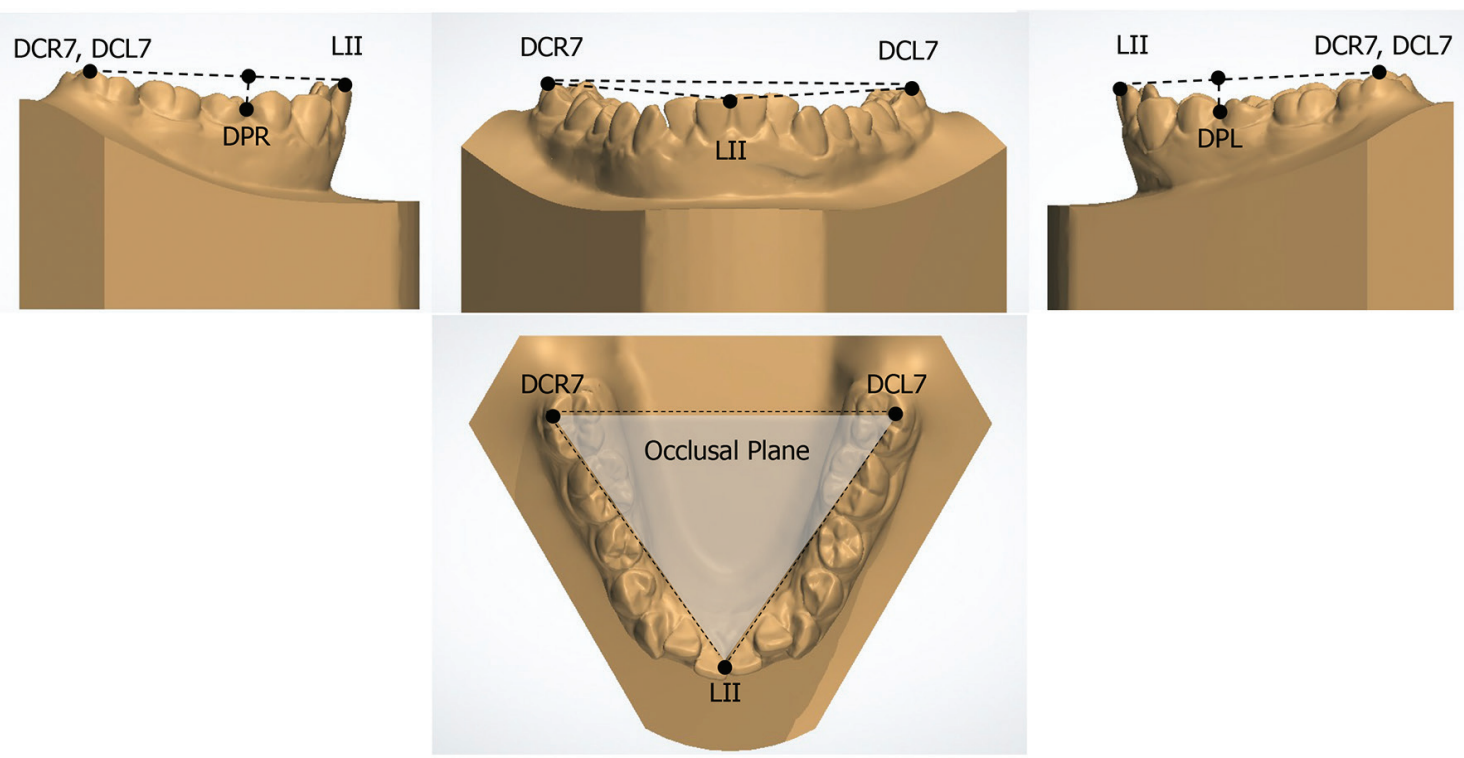

Figure 3. Digital model landmarks, reference plane, and measurement. DCR7, distobuccal cusps of the right second molar; DCL7, distobuccal cusps of the left second molar; LII, midpoint between the lower central incisors; DPR, deepest point of the right mandibular arch; DPL, deepest point of the left mandibular arch; occlusal plane, plane defined by DCR7, DCL7, and LII; COS, mean value between perpendicular distances from the occlusal plane to DCR7 and DCL7.

Two years after the end of treatment, the low-angle group showed a significant relapse of lower incisors inclination (IMPA: $-3.48^{\circ}$ ) and vertical position (L1-MP: $-1.36 \mathrm{~mm}$ ) with respect to the normal-angle (IMPA: $-0.80^{\circ}$; L1-MP: $-0.42 \mathrm{~mm}$ ) and the high-angle
(IMPA: $-0.70^{\circ}$; L1-MP: $-0.41 \mathrm{~mm}$ ) groups. In the post-treatment evaluation, the high-angle group exhibited a greater stability of interincisal angle (Int.Inc.: $+1.22^{\circ}$ ) with respect to the normal-angle (Int.Inc.: $+2.59^{\circ}$ ) and the low-angle (Int.Inc.: $+2.26^{\circ}$ ) groups. 
On the contrary, the first and second molars in the high-angle group showed an increase of axial angulation to the mandibular plane (L6^ $\mathrm{MP}:+2.40^{\circ} ; \mathrm{L}^{\wedge} \mathrm{MP}:+2.54^{\circ}$ ) when compared to the lowangle group (L6 $6^{\wedge} \mathrm{MP}:+1.02^{\circ}$; $\left.\mathrm{L}^{\wedge} \mathrm{MP}:+1.02^{\circ}\right)$.

Greater relapse in the $\mathrm{COS}$ and overbite values was evident in the low-angle group (SPEE: $+1.52 \mathrm{~mm}$; OVB: $+1.70 \mathrm{~mm}$ ) with respect to the high-angle group (SPEE: $+0.53 \mathrm{~mm}$; OVB: $+0.52 \mathrm{~mm}$ ). No patients had angular changes greater than $10^{\circ}$ for any tooth analysed.

\section{Discussion}

The aim of this study was to evaluate the long-term stability of COS depth in patients with different vertical patterns 2 years after the end of treatment with fixed appliances and continuous archwires. To the best of our knowledge, no previous study completely described the

Table 3. The normal distribution of the data (results for Kolmogorov-Smirnov test). $Z$, Kolmogorov-Smirnov $Z ; P, P$ value; low-angle, low-angle group; normal-angle, normal-angle group; high-angle, high-angle group

\begin{tabular}{lccc}
\hline & & T1 & T2 \\
\hline Low-angle & $Z$ & 0.56 & 0.58 \\
Normal-angle & $P$ & 0.87 & 0.76 \\
& $Z$ & 0.52 & 0.59 \\
High-angle & $P$ & 0.94 & 0.87 \\
& $Z$ & 0.50 & 0.51 \\
& $P$ & 0.67 & 0.74 \\
\hline
\end{tabular}

Significant at $P<0.05$. causes for the different range of relapse existing between vertical facial patterns.

Tooth alignment and COS levelling require increase in arch perimeter caused by incisor advancement and transverse expansion. The primary factors influencing occlusal changes during treatment with continuous archwires appear to be initial crowding and incisor inclination (16). For these reasons, the three subgroups were matched for Little's Irregularity Index and IMPA values at baseline (12). In this study, the COS depth was not related to gender. The lack of sexual dimorphism is in agreement with previous two-dimensional $(17,18)$ and three-dimensional $(19)$ evaluation of the occlusal curvature.

Many orthodontists overcorrect the COS with the expectation of relapse due to teeth eruption, orofacial growth, and development of neuromuscular system (20). According to Farella et al. (21), the amount of COS depth was weakly influenced by initial vertical craniofacial dimensions. However, the levelling of COS during treatment and its long-term stability might depend on different skeletal vertical pattern. In agreement with a previous study (3), it was observed that vertical dimension determined different dental movements during COS levelling with continuous archwire technique. In the lowangle subjects, COS levelling occurred mainly through advancement and intrusion of lower incisors (IMPA: $+6.71^{\circ}$; L1-MP: $-2.03 \mathrm{~mm}$ ), whereas in the high-angle patients, the COS was flattened through extrusion (L4-MP: +3.62 mm; L6-MP: $+2.24 \mathrm{~mm}$ ) and uprighting of lower posterior teeth (L6^ $6^{\wedge}$ : $-4.00^{\circ}$; $\mathrm{L}^{\wedge} \mathrm{MP}:-3.38^{\circ}$ ).

Shannon and Nanda (22) defined intrusion and proclination of lower incisors as unstable movements. As suggested also by Canut and Arias (23), the long-term instability of flared incisors might explain the relapse of both overbite and COS depth observed in the low-angle group (SPEE: $+1.52 \mathrm{~mm}$; OVB: $+1.70 \mathrm{~mm}$ ) (11).

Table 4. Descriptive statistics and statistical comparisons (independent-samples $t$-tests) of the starting forms (cephalometric values at T1). $\mathrm{SD}$, standard deviation

\begin{tabular}{|c|c|c|c|c|c|c|c|}
\hline \multirow[b]{2}{*}{ Variables } & \multicolumn{2}{|c|}{ Low-angle group (10 M, $11 \mathrm{~F})$} & \multicolumn{2}{|c|}{ Normal-angle group (9 M, $11 \mathrm{~F}$ ) } & \multicolumn{2}{|c|}{ High-angle group ( $8 \mathrm{M}, 11 \mathrm{~F})$} & \multirow[b]{2}{*}{$P<0.01$} \\
\hline & Mean \pm SD & SEM & Mean $\pm S D$ & SEM & Mean \pm SD & SEM & \\
\hline $\operatorname{SNA}\left({ }^{\circ}\right)$ & $81.23 \pm 5.23$ & 1.14 & $81.40 \pm 4.65$ & 1.03 & $80.3 \pm 4.10$ & 0.94 & NS \\
\hline $\operatorname{SNB}\left({ }^{\circ}\right)$ & $76.48 \pm 4.86$ & 1.06 & $76.90 \pm 5.29$ & 1.18 & $74.81 \pm 5.48$ & 1.26 & NS \\
\hline $\operatorname{ANB}\left({ }^{\circ}\right)$ & $4.75 \pm 2.27$ & 0.49 & $4.50 \pm 2.86$ & 0.64 & $5.50 \pm 3.12$ & 0.71 & NS \\
\hline $\mathrm{SN}^{\wedge} \mathrm{GoGn}\left({ }^{\circ}\right)$ & $28.76 \pm 3.75$ & 0.82 & $33.84 \pm 4.53$ & 1.01 & $42.15 \pm 3.98$ & 0.91 & $* *$ \\
\hline $\operatorname{FMA}\left({ }^{\circ}\right)$ & $19.46 \pm 2.36$ & 0.52 & $26.36 \pm 2.84$ & 0.63 & $33.21 \pm 3.28$ & 075 & $* *$ \\
\hline $\mathrm{y}$-axis $\left({ }^{\circ}\right)$ & $55.73 \pm 4.63$ & 1.01 & $59.72 \pm 4.29$ & 0.95 & $65.82 \pm 5.53$ & 1.27 & $* *$ \\
\hline $\mathrm{SN} \wedge \mathrm{OP}\left({ }^{\circ}\right)$ & $21.84 \pm 3.85$ & 0.84 & $23.95 \pm 3.14$ & 0.70 & $25.05 \pm 3.07$ & 0.70 & NS \\
\hline $\mathrm{OP}^{\wedge} \mathrm{MP}\left({ }^{\circ}\right)$ & $10.53 \pm 2.70$ & 0.59 & $11.75 \pm 3.09$ & 0.69 & $13.35 \pm 2.64$ & 0.60 & NS \\
\hline $\mathrm{SN}^{\wedge} \mathrm{PP}\left({ }^{\circ}\right)$ & $7.73 \pm 2.09$ & 5.44 & $8.39 \pm 1.93$ & 0.43 & $9.02 \pm 1.38$ & 0.32 & NS \\
\hline $\operatorname{IMPA}\left({ }^{\circ}\right)$ & $95.33 \pm 6.83$ & 1.49 & $94.93 \pm 7.26$ & 1.62 & $93.99 \pm 4.79$ & 1.09 & NS \\
\hline Up.Inc. ${ }^{\wedge} \mathrm{FP}\left({ }^{\circ}\right)$ & $111.97 \pm 7.28$ & 1.59 & $113.43 \pm 8.49$ & 1.89 & $112.93 \pm 7.79$ & 1.78 & NS \\
\hline $\mathrm{OVJ}(\mathrm{mm})$ & $5.81 \pm 2.97$ & 0.65 & $4.93 \pm 2.69$ & 0.60 & $5.28 \pm 3.19$ & 0.73 & NS \\
\hline OVB (mm) & $4.34 \pm 2.65$ & 0.58 & $3.79 \pm 2.82$ & 0.63 & $3.56 \pm 2.37$ & 0.54 & NS \\
\hline Int.Inc. $\left({ }^{\circ}\right)$ & $128.13 \pm 9.15$ & 1.99 & $126.79 \pm 8.75$ & 1.96 & $126.02 \pm 8.82$ & 2.02 & NS \\
\hline L1-MP (mm) & $37.65 \pm 5.29$ & 1.15 & $37.81 \pm 4.19$ & 0.94 & $38.91 \pm 4.66$ & 1.06 & NS \\
\hline L4-MP (mm) & $29.65 \pm 2.89$ & 0.63 & $28.86 \pm 3.08$ & 0.68 & $29.94 \pm 3.84$ & 0.88 & NS \\
\hline L6-MP (mm) & $25.89 \pm 2.73$ & 0.59 & $25.50 \pm 3.17$ & 0.71 & $28.47 \pm 2.60$ & 0.59 & NS \\
\hline L7-MP (mm) & $24.84 \pm 3.60$ & 0.78 & $24.46 \pm 2.81$ & 0.63 & $26.56 \pm 2.04$ & 0.47 & NS \\
\hline U1-PP (mm) & $27.83 \pm 3.14$ & 0.68 & $27.95 \pm 3.08$ & 0.69 & $28.46 \pm 2.30$ & 0.53 & NS \\
\hline $\mathrm{L} 6^{\wedge} \mathrm{MP}\left({ }^{\circ}\right)$ & $86.57 \pm 5.02$ & 1.09 & $85.98 \pm 3.86$ & 0.86 & $85.35 \pm 4.89$ & 1.12 & NS \\
\hline $\mathrm{L} 7^{\wedge} \mathrm{MP}\left({ }^{\circ}\right)$ & $89.04 \pm 6.29$ & 1.37 & $87.33 \pm 5.56$ & 1.24 & $87.87 \pm 6.08$ & 1.39 & NS \\
\hline SPEE (mm) & $4.53 \pm 1.82$ & 0.39 & $4.02 \pm 2.05$ & 0.46 & $3.78 \pm 1.47$ & 0.34 & NS \\
\hline
\end{tabular}

Refer to Table 1 for the definition of cephalometric measurements.

$* * P<0.01$; NS, not significant. 
Table 5. Mean measurements for the pre-treatment curve of Spee depth for male and female patients or for right and left sides ( $m m$ ). Dx, curve of Spee on right side; Sx, curve of Spee on left side; Mean, mean value of curve of Spee on left and right sides; low-angle, low-angle group; normal-angle, normal-angle group; high-angle, high-angle group

\begin{tabular}{|c|c|c|c|c|c|c|c|}
\hline \multirow[b]{2}{*}{ Groups } & \multicolumn{3}{|l|}{ Males } & \multicolumn{3}{|l|}{ Females } & \multirow[b]{2}{*}{$P$ valu } \\
\hline & $\mathrm{Dx}($ mean $\pm \mathrm{SD})$ & $\mathrm{Sx}($ mean $\pm \mathrm{SD})$ & $\begin{array}{l}\text { Mean Dx-Sx } \\
(\text { mean } \pm S D)\end{array}$ & $\mathrm{Dx}($ mean $\pm \mathrm{SD})$ & $\mathrm{Sx}($ mean $\pm \mathrm{SD})$ & $\begin{array}{l}\text { Mean Dx-Sx } \\
(\text { mean } \pm S D)\end{array}$ & \\
\hline Low-angle & $4.46 \pm 0.82$ & $4.40 \pm 0.93$ & $4.43 \pm 0.79$ & $4.35 \pm 0.86$ & $4.44 \pm 0.89$ & $4.39 \pm 0.87$ & 0.56 \\
\hline Normal-angle & $3.83 \pm 0.71$ & $3.79 \pm 0.76$ & $3.81 \pm 0.86$ & $3.72 \pm 0.86$ & $3.86 \pm 0.97$ & $3.79 \pm 0.90$ & 0.62 \\
\hline High-angle & $3.92 \pm 0.92$ & $3.84 \pm 0.78$ & $3.88 \pm 0.87$ & $3.89 \pm 0.79$ & $3.96 \pm 0.83$ & $3.92 \pm 0.80$ & 0.59 \\
\hline
\end{tabular}

Values are presented as mean \pm standard deviation. Multicomparison analysis of variance test was used. $* P<0.01$.

Table 6. Statistical comparison of the changes (T1 to T2) during treatment between the groups. Low-angle (I), low-angle group; normalangle (II), normal-angle group; high-angle (III), high-angle group; SPEE, curve of Spee measured on digital model

\begin{tabular}{|c|c|c|c|c|c|c|c|c|c|}
\hline \multirow[b]{3}{*}{ Variable } & \multirow{2}{*}{\multicolumn{2}{|c|}{$\frac{\text { Low-angle (I) }}{\text { T2-T1 }}$}} & \multirow{2}{*}{\multicolumn{2}{|c|}{$\frac{\text { Normal-angle (II) }}{\text { T2-T1 }}$}} & \multirow{2}{*}{\multicolumn{2}{|c|}{$\frac{\text { High-angle (III) }}{\text { T2-T1 }}$}} & \multirow{2}{*}{\multicolumn{3}{|c|}{ Intergroup comparison, $P$ value }} \\
\hline & & & & & & & & & \\
\hline & Mean \pm SD & SEM & Mean \pm SD & SEM & Mean \pm SD & SEM & I-II & I-III & II-III \\
\hline $\operatorname{SNA}\left({ }^{\circ}\right)$ & $-0.28 \pm 0.18$ & 0.04 & $0.09 \pm 0.07$ & 0.01 & $-0.77 \pm 0.52$ & 0.12 & -0.19 & 0.49 & 0.68 \\
\hline $\operatorname{SNB}\left({ }^{\circ}\right)$ & $0.24 \pm 0.15$ & 0.03 & $0.64 \pm 0.52$ & 0.12 & $-0.84 \pm 0.82$ & 0.19 & -0.40 & 0.60 & 1.48 \\
\hline $\operatorname{ANB}\left({ }^{\circ}\right)$ & $-0.66 \pm 0.50$ & 0.10 & $-0.47 \pm 0.61$ & 0.14 & $-0.41 \pm 0.31$ & 0.07 & 0.19 & -0.25 & -0.06 \\
\hline $\mathrm{SN}^{\wedge} \mathrm{GoGn}\left({ }^{\circ}\right)$ & $-0.25 \pm 0.32$ & 0.06 & $0.38 \pm 0.25$ & 0.05 & $0.09 \pm 0.03$ & 0.01 & -0.63 & -0.34 & 0.29 \\
\hline FMA $\left(^{\circ}\right)$ & $0.34 \pm 0.21$ & 0.05 & $0.82 \pm 0.53$ & 0.12 & $0.63 \pm 0.27$ & 0.06 & -0.48 & -0.29 & 0.19 \\
\hline$y$-axis $\left({ }^{\circ}\right)$ & $0.64 \pm 0.25$ & 0.05 & $0.68 \pm 0.70$ & 0.16 & $1.02 \pm 0.69$ & 0.16 & -0.04 & -0.38 & -0.34 \\
\hline $\mathrm{SN}^{\wedge} \mathrm{OP}\left({ }^{\circ}\right)$ & $1.18 \pm 1.01$ & 0.22 & $1.65 \pm 0.97$ & 0.22 & $2.27 \pm 1.26$ & 0.29 & -0.47 & -1.09 & -0.62 \\
\hline $\mathrm{OP}^{\wedge} \mathrm{MP}\left({ }^{\circ}\right)$ & $-1.23 \pm 0.92$ & 0.20 & $-2.76 \pm 0.78$ & 0.17 & $-3.40 \pm 1.24$ & 0.28 & $1.53^{*}$ & $2.17^{*}$ & 0.64 \\
\hline $\mathrm{SN}^{\wedge} \mathrm{PP}\left({ }^{\circ}\right)$ & $0.45 \pm 0.26$ & 0.06 & $0.56 \pm 0.41$ & 0.09 & $0.91 \pm 0.33$ & 0.07 & -0.11 & -0.46 & -0.35 \\
\hline $\operatorname{IMPA}\left({ }^{\circ}\right)$ & $6.71 \pm 4.31$ & 0.94 & $1.72 \pm 1.09$ & 0.24 & $0.54 \pm 0.26$ & 0.06 & $4.99 *$ & $6.17^{*}$ & 1.18 \\
\hline Up.Inc. ${ }^{\wedge} \mathrm{F}\left({ }^{\circ}\right)$ & $-0.85 \pm 0.6$ & 0.13 & $-1.13 \pm 0.64$ & 0.14 & $-1.46 \pm 1.23$ & 0.28 & 0.28 & 0.61 & 0.33 \\
\hline OVJ (mm) & $-2.04 \pm 1.27$ & 0.27 & $-2.18 \pm 1.43$ & 0.32 & $-2.67 \pm 1.59$ & 0.36 & 0.14 & 0.63 & 0.49 \\
\hline OVB (mm) & $-3.37 \pm 1.52$ & 0.33 & $-2.75 \pm 1.26$ & 0.28 & $-2.65 \pm 0.75$ & 0.17 & -0.62 & -0.72 & -0.10 \\
\hline Int.Inc. $\left({ }^{\circ}\right)$ & $-5.83 \pm 3.90$ & 0.85 & $-6.27 \pm 2.76$ & 0.62 & $-2.75 \pm 1.16$ & 0.27 & 0.44 & $-3.08 *$ & $-3.52 *$ \\
\hline L1-MP (mm) & $-2.03 \pm 0.90$ & 0.19 & $-0.85 \pm 0.94$ & 0.21 & $-0.26 \pm 0.08$ & 0.02 & $-1.18 *$ & $-1.77 *$ & -0.59 \\
\hline L4-MP (mm) & $0.79 \pm 0.62$ & 0.13 & $2.35 \pm 1.41$ & 0.31 & $3.62 \pm 1.66$ & 0.38 & -1.56 & $-2.83^{*}$ & -1.27 \\
\hline L6-MP (mm) & $0.45 \pm 0.21$ & 0.04 & $1.46 \pm 0.84$ & 0.19 & $2.24 \pm 0.77$ & 0.18 & -1.01 & $-1.79 *$ & -0.78 \\
\hline L7-MP (mm) & $-0.65 \pm 0.20$ & 0.04 & $0.89 \pm 0.55$ & 0.12 & $1.24 \pm 0.37$ & 0.08 & -1.54 & -1.89 & -0.35 \\
\hline U1-PP (mm) & $-0.67 \pm 0.41$ & 0.09 & $-0.71 \pm 0.26$ & 0.06 & $-0.93 \pm 0.45$ & 0.10 & -0.04 & 0.26 & 0.22 \\
\hline $\mathrm{L} 6^{\wedge} \mathrm{MP}\left({ }^{\circ}\right)$ & $-1.82 \pm 0.64$ & 0.14 & $-2.85 \pm 1.07$ & 0.24 & $-4.00 \pm 4.24$ & 0.97 & 1.03 & $2.18^{*}$ & 1.15 \\
\hline $\mathrm{L} 7^{\wedge} \mathrm{MP}\left({ }^{\circ}\right)$ & $-1.78 \pm 0.94$ & 0.20 & $-2.47 \pm 0.31$ & 0.07 & $-3.38 \pm 0.95$ & 0.22 & 0.69 & $1.60 *$ & 0.91 \\
\hline SPEE $(\mathrm{mm})$ & $-2.87 \pm 0.57$ & 0.12 & $-2.26 \pm 0.45$ & 0.10 & $-2.08 \pm 0.78$ & 0.18 & -0.61 & $-0,79$ & -0.18 \\
\hline
\end{tabular}

Values are presented as mean \pm standard deviation and SEM. Multicomparison analysis of variance test confirmed by pair-wise bivariate $t$-test was used. Refer to Table 1 for the definition of each measurements.

$$
\text { *P }<0.01 \text {. }
$$

Indeed, the low-angle and the normal-angle groups showed a significant reduction in interincisal angle (Int.Inc.: $-5.83^{\circ}$ and $-6.27^{\circ}$ respectively) due to lower incisor proclination during treatment. Those values relapsed significantly due to an uprighting of mandibular incisors at T3. Especially in the low-angle group, a significant relapse of lower incisors inclination (IMPA: $-3.48^{\circ}$ ) and vertical position (L1$\mathrm{MP},+1.36 \mathrm{~mm}$ ) was observed. On the contrary, the high-angle group exhibited no significant long-term changes of interincisal angle and a greater stability of COS and overbite (SPEE: $+0.53 \mathrm{~mm}$; OVB: $+0.52 \mathrm{~mm}$ ) obtained by stable extrusion of posterior teeth (L4-MP, -1.02 mm; L6-MP, -0.48 mm). Many authors (14,24-27) reported mandibular clockwise rotation and increased anterior face height associated with the extrusion of maxillary and mandibular molars during COS levelling with continuous archwire technique. In this study, these changes did not affect any skeletal vertical variable, even in high-angle patients (3).

Previous authors as McAlpine and colleagues (28) and Pollard et al. (11) found that the greatest amounts of relapse in treated deep bite patients were in the subjects with brachycephalic patterns characterized by short lower anterior face heights and low mandibular plane angles. Probably, the subgroup differences for extrusion of posterior teeth, proclination, and intrusion of lower incisors were related to differences in mandibular muscle morphology and to larger masseters in brachyfacial patients than in dolichofacial individuals $(29,30)$. Different magnitude in biting forces between highangle and low-angle patients plays an important role in the balance between molar extrusion and incisor intrusion. Heavier masticatory forces in low-angle group could have precluded the overeruption of 
Table 7. Statistical comparison of the changes (T2 to T3) between the groups. Low-angle (I), low-angle group; normal-angle (II), normalangle group; high-angle (III), high-angle group; SPEE, curve of Spee measured on digital model

\begin{tabular}{|c|c|c|c|c|c|c|c|c|c|}
\hline \multirow[b]{3}{*}{ Variable } & \multirow{2}{*}{\multicolumn{2}{|c|}{$\frac{\text { Low-angle (I) }}{\text { T3-T2 }}$}} & \multirow{2}{*}{\multicolumn{2}{|c|}{$\begin{array}{l}\text { Normal-angle (II) } \\
\text { T3-T2 }\end{array}$}} & \multirow{2}{*}{\multicolumn{2}{|c|}{$\begin{array}{l}\text { High-angle (III) } \\
\text { T3-T2 }\end{array}$}} & \multirow{2}{*}{\multicolumn{3}{|c|}{ Intergroup comparison, $P$ value }} \\
\hline & & & & & & & & & \\
\hline & Mean \pm SD & SEM & Mean \pm SD & SEM & Mean \pm SD & SEM & I-II & I-III & II-III \\
\hline SNA $\left({ }^{\circ}\right)$ & $0.45 \pm 0.06$ & 0.01 & $0.39 \pm 0.05$ & 0.01 & $0.61 \pm 0.08$ & 0.02 & 0.06 & -0.16 & -0.22 \\
\hline $\operatorname{SNB}\left({ }^{\circ}\right)$ & $0.36 \pm 0.05$ & 0.01 & $0.57 \pm 0.03$ & 0.01 & $-0.24 \pm 0.03$ & 0.01 & -0.21 & 0.60 & 0.81 \\
\hline ANB $\left({ }^{\circ}\right)$ & $0.33 \pm 0.08$ & 0.02 & $-0.27 \pm 0.04$ & 0.01 & $0.61 \pm 0.07$ & 0.02 & 0.6 & -0.28 & -0.88 \\
\hline $\mathrm{SN}^{\wedge} \mathrm{GoGn}\left({ }^{\circ}\right)$ & $0.34 \pm 0.12$ & 0.03 & $-0.53 \pm 0.38$ & 0.08 & $-0.46 \pm 0.33$ & 0.07 & 0.87 & 0.8 & -0.07 \\
\hline FMA $\left(^{\circ}\right)$ & $-0.86 \pm 0.11$ & 0.02 & $-0.32 \pm 0.08$ & 0.02 & $-0.23 \pm 0.07$ & 0.02 & -0.54 & -0.63 & -0.09 \\
\hline $\mathrm{y}$-axis $\left({ }^{\circ}\right)$ & $-0.74 \pm 0.38$ & 0.08 & $-0.46 \pm 0.43$ & 0.10 & $-0.24 \pm 0.47$ & 0.11 & -0.28 & -0.50 & -0.22 \\
\hline $\mathrm{SN}^{\wedge} \mathrm{OP}\left({ }^{\circ}\right)$ & $-0.87 \pm 0.54$ & 0.12 & $-0.41 \pm 0.26$ & 0.06 & $-0.47 \pm 0.27$ & 0.06 & -0.46 & -0.40 & -0.06 \\
\hline $\mathrm{OP}^{\wedge} \mathrm{MP}\left({ }^{\circ}\right)$ & $0.45 \pm 0.18$ & 0.04 & $1.09 \pm 0.71$ & 0.16 & $0.84 \pm 0.52$ & 0.12 & -0.64 & -0.39 & 0.25 \\
\hline $\mathrm{SN}^{\wedge} \mathrm{PP}\left({ }^{\circ}\right)$ & $-0.36 \pm 0.12$ & 0.03 & $-0.42 \pm 0.23$ & 0.05 & $0.27 \pm 0.05$ & 0.01 & -0.06 & -0.63 & -0.69 \\
\hline $\operatorname{IMPA}\left({ }^{\circ}\right)$ & $-3.48 \pm 1.24$ & 0.27 & $-0.80 \pm 0.89$ & 0.20 & $-0.70 \pm 0.09$ & 0.02 & $-2.68 *$ & $-2.78^{*}$ & -0.1 \\
\hline Up.Inc. ${ }^{\wedge} \mathrm{FP}\left({ }^{\circ}\right)$ & $0.43 \pm 0.31$ & 0.07 & $0.74 \pm 0.47$ & 0.10 & $0.84 \pm 0.63$ & 0.14 & -0.31 & -0.41 & -0.10 \\
\hline OVJ (mm) & $1.57 \pm 0.83$ & 0.18 & $0.86 \pm 0.52$ & 0.12 & $0.60 \pm 0.59$ & 0.13 & 0.71 & 0.97 & 0.26 \\
\hline OVB $(\mathrm{mm})$ & $1.70 \pm 0.58$ & 0.13 & $0.73 \pm 0.48$ & 0.12 & $0.52 \pm 0.12$ & 0.03 & 0.97 & $1.18 *$ & 0.21 \\
\hline Int.Inc. $\left({ }^{\circ}\right)$ & $2.26 \pm 0.90$ & 0.19 & $2.59 \pm 1.08$ & 0.24 & $1.22 \pm 0.48$ & 0.11 & -0.33 & $1.04 *$ & $1.37^{* \prime}$ \\
\hline L1-MP (mm) & $1.36 \pm 0.50$ & 0.11 & $0.42 \pm 0.2$ & 0.04 & $0.14 \pm 0.03$ & 0.01 & $0.94 *$ & $1.22 *$ & 0.28 \\
\hline L4-MP (mm) & $-0.52 \pm 0.12$ & 0.03 & $-1.07 \pm 0.54$ & 0.12 & $-1.02 \pm 0.34$ & 0.08 & 0.55 & 0.50 & 0.05 \\
\hline L6-MP (mm) & $-0.37 \pm 0.26$ & 0.06 & $-0.85 \pm 0.26$ & 0.06 & $-0.48 \pm 0.09$ & 0.02 & 0.48 & 0.11 & -0.37 \\
\hline L7-MP (mm) & $0.31 \pm 0.10$ & 0.02 & $-0.36 \pm 0.24$ & 0.05 & $-0.51 \pm 0.18$ & 0.04 & 0.67 & 0.82 & 0.15 \\
\hline U1-PP (mm) & $0.58 \pm 0.41$ & 0.09 & $0.34 \pm 0.29$ & 0.06 & $0.31 \pm 0.08$ & 0.02 & 0.24 & 0.27 & 0.03 \\
\hline $\mathrm{L} 6^{\wedge} \mathrm{MP}\left({ }^{\circ}\right)$ & $1.02 \pm 0.04$ & 0.01 & $1.93 \pm 0.73$ & 0.16 & $2.40 \pm 1.25$ & 0.28 & -0.91 & $1.38 *$ & -0.47 \\
\hline $\mathrm{L} 7^{\wedge} \mathrm{MP}\left({ }^{\circ}\right)$ & $1.02 \pm 0.32$ & 0.07 & $1.75 \pm 0.31$ & 0.07 & $2.54 \pm 0.95$ & 0.22 & -0.73 & $-1.52 *$ & -0.79 \\
\hline SPEE (mm) & $1.52 \pm 0.45$ & 0.09 & $1.08 \pm 0.28$ & 0.89 & $0.53 \pm 0.04$ & 0.01 & 0.44 & $0.99 *$ & 0.55 \\
\hline
\end{tabular}

Values are presented as mean \pm standard deviation and SEM. Multicomparison analysis of variance test confirmed by pair-wise bivariate $t$-test was used. Refer to Table 1 for the definition of each measurements.

$$
{ }^{*} P<0.01 \text {. }
$$

posterior teeth while allowing intrusion and proclination of lower incisors (3,29-31).

Several authors have described deep bite malocclusions as relapse prone $(32,33)$. In a study by Berg $(32)$, relapse reduced treatment effect by 18.8 per cent on average in 26 patients with deep bite malocclusion after 5-9 years out of retention. Relapse of deep bite was reported 10 years after treatment in 23 consecutive patients to almost pre-treatment levels, although Hawley plates as retention devices were used in most of the patients (34). Lapatki et al. (35) investigated a sample with deep bite and retroclined incisors and found 20 per cent of vertical relapse on median 2 years after treatment. Several findings regarding deep bite relapse are reported from studies investigating samples with other malocclusions. The COS in a Class II division 1 sample was reported to gradually relapse over the years (14). Similarly, a positive correlation between years out of retention and overbite relapse was found in another Class II division 2 sample (23). In 80 per cent of short facial type patients, a post-treatment increase in overbite was recorded 2 years after treatment completion despite the use of removable retention for 1 year (36).

In the cases with dentoalveolar deep bite and successful treatment with subsequent retention by fixed retainers and a temporary removable upper plate, the prevalence and degree of deep bite relapse were relatively small and clinically insignificant (37).

Therefore, the use of fixed lingual retainer in all deep bite cases, in particular in brachyfacial patients, could be important to avoid the relapse of lower proclination, intrusion, and alignment of lower incisors.

\section{Conclusion}

The levelling of COS during treatment and its long term-stability was influenced by different skeletal vertical pattern. In the lowangle subjects, COS levelling occurred mainly through advancement and intrusion of lower incisors, whereas in the high-angle patients the COS was flattened through extrusion and uprighting of lower posterior teeth. Two years after the end of treatment, brachyfacial patients showed an increase relapse of COS and overbite due to unstable proclination and intrusion of lower incisors. On the contrary, in the high-angle group, the COS depth was maintained stable as well as the extrusion of posterior teeth.

\section{Conflict of interest}

None declared.

\section{References}

1. Ahammed, A.R., Ganiger, C.C., Shetty, V., Sunny, S., Shetty, S., Pawar, R. and Suresh, K.V. (2014) Post-retention development of curve of Spee in pre-adjusted edgewise appliance cases, its correlation to dentoskeletal parameters: an in vitro study. Journal of International Oral Health, 6, 31-35.

2. Andrews, L.F. (1972) The six keys to normal occlusion. American Journal of Orthodontics, 62, 296-309.

3. Rozzi, M., Mucedero, M., Pezzuto, C. and Cozza, P. (2017) Leveling the curve of Spee with continuous archwire appliances in different vertical skeletal patterns: a retrospective study. American Journal of Orthodontics and Dentofacial Orthopedics, 151, 758-766. 
4. Koyama, T. (1979) A comparative analysis of the curve of Spee (lateral aspect) before and after orthodontic treatment-with particular reference to overbite patients. The Journal of Nihon University School of Dentistry, 21, 25-34.

5. Garcia, R. (1985) Leveling the curve of Spee: a new prediction formula. Journal of the Charles H. Tweed International Foundation, 13, 65-72.

6. Weinberg, M. and Sadowsky, C. (1996) Resolution of mandibular arch crowding in growing patients with Class I malocclusions treated nonextraction. American Journal of Orthodontics and Dentofacial Orthopedics, 110, 359-364.

7. Spee, F.G., Biedenbach, M.A., Hotz, M. and Hitchcock, H.P. (1980) The gliding path of the mandible along the skull. Journal of American Dental Association, 100, 670-675.

8. Marshall, S.D., Caspersen, M., Hardinger, R.R., Franciscus, R.G., Aquilino, S.A. and Southard, T.E. (2008) Development of the curve of Spee. American Journal of Orthodontics and Dentofacial Orthopedics, 134, 344-352.

9. Carter, G.A. and McNamara, J.A. Jr. (1998) Longitudinal dental arch changes in adults. American Journal of Orthodontics and Dentofacial Orthopedics, 114, 88-99.

10. Kuitert, R.B., van Ginkel, F.C. and Prahl-Andersen, B. (2000) Development of the curve of Spee during and after orthodontic treatment [abstract]. European Journal of Orthodontics, 22, 596.

11. Pollard, D., Akyalcin, S., Wiltshire, W.A. and Rody, W.J., Jr. (2012) Relapse of orthodontically corrected deepbites in accordance with growth pattern. American Journal of Orthodontics and Dentofacial Orthopedics, 141, 477-483.

12. Little, R.M. (1975) The irregularity index: a quantitative score of mandibular anterior alignment. American Journal of Orthodontics, 68, 554-563.

13. Baccetti, T., Franchi, L. and McNamara J.A., Jr. (2005) The cervical vertebral maturation (CVM) method for the assessment of optimal treatment timing in dentofacial orthopedics. Seminars Orthodontics, 11, 119-129.

14. Bernstein, R.L., Preston, C.B. and Lampasso, J. (2007) Leveling the curve of Spee with a continuous archwire technique: a long term cephalometric study. American Journal of Orthodontics and Dentofacial Orthopedics, 131, 363-371.

15. Bimler, H.P. (1985) Bimler therapy. Part 1. Bimler cephalometric analysis. Journal of Clinical Orthodontics, 19, 501-523.

16. Fleming, P.S., DiBiase, A.T., Sarri, G. and Lee, R.T. (2009) Comparison of mandibular arch changes during alignment and leveling with 2 preadjusted edgewise appliances. American Journal of Orthodontics and Dentofacial Orthopedics, 136, 340-347.

17. Orthlieb, J.D. (1997) The curve of Spee: understanding the sagittal organization of mandibular teeth. Cranio: The Journal of Craniomandibular Practice, 15, 333-340.

18. Ferrario, V.F., Sforza, C., Miani, A. Jr, Colombo, A. and Tartaglia, G. (1992) Mathematical definition of the curve of Spee in permanent healthy dentitions in man. Archives of Oral Biology, 37, 691-694.

19. Ferrario, V.F., Sforza, C. and Miani, A., Jr. (1997) Statistical evaluation of Monson's sphere in healthy permanent dentitions in man. Archives of Oral Biology, 42, 365-369.
20. Ahmed, I., Nazir, R., Gul-e-Erum and Ahsan, T. (2011) Influence of malocclusion on the depth of curve of Spee. JPMA. The Journal of the Pakistan Medical Association, 61, 1056-1059.

21. Farella, M., Michelotti, A., van Eijden, T.M. and Martina, R. (2002) The curve of Spee and craniofacial morphology: a multiple regression analysis. European Journal of Oral Sciences, 110, 277-281.

22. Shannon, K.R. and Nanda, R.S. (2004) Changes in the curve of Spee with treatment and at 2 years posttreatment. American Journal of Orthodontics and Dentofacial Orthopedics, 125, 589-596.

23. Canut, J.A. and Arias, S. (1999) A long-term evaluation of treated Class II division 2 malocclusions: a retrospective study model analysis. European Journal of Orthodontics, 21, 377-386.

24. Otto, R.L., Anholm, J.M. and Engel, G.A. (1980) A comparative analysis of intrusion of incisor teeth achieved in adults and children according to facial type. American Journal of Orthodontics, 77, 437-446.

25. Weiland, F.J., Bantleon, H.P. and Droschl, H. (1996) Evaluation of continuous arch and segmented arch leveling techniques in adult patientsa clinical study. American Journal of Orthodontics and Dentofacial Orthopedics, 110, 647-652.

26. Wylie, W.L. (1944) Overbite and vertical facial dimensions in terms of muscle balance. The Angle Orthodontist, 14, 13-17.

27. Bench, R.W., Gugino, C.F. and Hilgers, J.J. (1977) Bio-progressive therapy. Journal of Clinical Orthodontics, 11, 661-71, 674.

28. Engel, G., Cornforth, G., Damerell, J.M., Gordon, J., Levy, P., McAlpine, J., Otto, R., Walters, R. and Chaconas, S. (1980) Treatment of deep-bite cases. American Journal of Orthodontics, 77, 1-13.

29. Proffit, W.R., Fields, H.W. and Nixon, W.L. (1983) Occlusal forces in normal- and long-face adults. Journal of Dental Research, 62, 566-570.

30. Chan, H.J., Woods, M. and Stella, D. (2008) Mandibular muscle morphology in children with different vertical facial patterns: a 3-dimensional computed tomography study. American Journal of Orthodontics and Dentofacial Orthopedics, 133, 10.e1-10.13.

31. Ringqvist, M. (1973) Isometric bite force and its relation to dimensions of the facial skeleton. Acta Odontologica Scandinavica, 31, 35-42.

32. Berg, R. (1983) Stability of deep overbite correction. European Journal of Orthodontics, 5, 75-83.

33. Binda, S.K., Kuijpers-Jagtman, A.M., Maertens, J.K. and van 't Hof, M.A. (1994) A long-term cephalometric evaluation of treated Class II division 2 malocclusions. European Journal of Orthodontics, 16, 301-308.

34. Rönnerman, A. and Larsson, E. (1981) Overjet, overbite, intercanine distance and root resorption in orthodontically treated patients. A ten year follow-up study. Swedish Dental Journal, 5, 21-27.

35. Lapatki, B.G., Klatt, A., Schulte-Mönting, J., Stein, S. and Jonas, I.E. (2004) A retrospective cephalometric study for the quantitative assessment of relapse factors in cover-bite treatment. Journal of Orofacial Orthopedics, $65,475-488$.

36. Zaher, A.R., Bishara, S.E. and Jakobsen, J.R. (1994) Posttreatment changes in different facial types. The Angle Orthodontist, 64, 425-436.

37. Danz, J.C., Greuter, C., Sifakakis, I., Fayed, M., Pandis, N. and Katsaros, C. (2014) Stability and relapse after orthodontic treatment of deep bite cases-a long-term follow-up study. European Journal of Orthodontics, 36, 522-530. 